\title{
Treatment of Brain Metastases Using Gamma Knife Radiosurgery - The Gold Standard
}

\author{
a report by \\ Bodo E Lippitz \\ Karolinska Gamma Knife Centre, Department of Neurosurgery, Karolinska University Hospital, Stockholm
}

DOI:10.17925/ENR.2008.03.01.81

Annually, about 4,300 patients per million people present with cancer According to conservative estimates about $8.5 \%$ of cancer patients will develop brain metastases, ${ }^{1}$ yet there is no general management strategy dealing with this situation. Treatment options include fractionated wholebrain radiotherapy (WBRT), microsurgical resections, ${ }^{2}$ radiosurgery with either Linac ${ }^{\circledR}$ or Gamma Knife ${ }^{\circledR}$ or, in some instances, supportive care only. Large retrospective studies demonstrate that the effect of conventional fractionated radiotherapy is limited, with a particularly negative prognosis for patients with multiple metastases or older patients. Furthermore, fractionated radiotherapy involves lengthy hospitalisation plus potential side effects, thereby affecting the patient's quality of life.

Cerebral metastases often cause the leading symptoms in cancer, therefore their local control is particularly important. Single-session Gamma Knife radiosurgery under local anaesthesia is the least invasive active and effective therapy for brain tumours and can be carried out without interrupting the systemic treatment or the eventual planned surgery of a primary cancer. Active and effective treatment of brain metastases has been shown to be important for the survival and quality of life..$^{3,4}$

The Gamma Knife principle is based on the mechanical focusing of 201 radiation sources, resulting in an extremely limited irradiated volume. By the addition of several focuses (isocentres), virtually any geometrical structure can be matched, thereby allowing the exclusive irradiation of the target within the brain, i.e. the metastasis in the current context. The Gamma Knife provides a steep radiation dose fall-off. This specific gradient in 3D guarantees that the surrounding tissue is exposed to only limited radiation and consequently is 'protected' against undesired radiation effects. The 3D precision of the radiation focus and dose gradient is unmatched by other technologies. These physical characteristics of radiosurgery allow treatment in one single session. Compared with radiosurgery, no study of conventional fractionated WBRT has shown superior results in terms of local control, quality of life or survival.

\section{Conventional Fractionated Radiotherapy}

Fractionated WBRT is a common conventional treatment for brain metastases; ${ }^{3}$ however, the results are disappointing. The results of WBRT for cerebral metastases have been summarised in a retrospective analysis of several Radiation Therapy Oncology Group (RTOG) studies consisting of 1,200 patients. Eighty per cent of patients were divided into recursive partitioning analysis (RPA) classes II and III with a median survival of fewer than 4.2 months. ${ }^{5}$ Another three recent large retrospective studies of patients with brain metastases treated with conventional fractionated radiotherapy revealed a median survival of 2.9-4 months. ${ }^{6-8} \mathrm{~A}$ large German retrospective study with 916 patients who had been operated on and treated with fractionated WBRT showed a median survival of 3.4 months. ${ }^{9}$ The subgroup of older patients (>65 years of age) with multiple brain metastases (and uncontrolled primary cancer) survived only 1.2 months with conventional radiotherapy. ${ }^{9}$ Therefore, conventional fractionated radiotherapy can not be considered sufficiently effective in the treatment of cerebral metastases.

\section{Gamma Knife Radiosurgery}

Gamma Knife radiosurgery is highly effective even for brain metastases that are otherwise resistant to conventional fractionated externalbeam radiation therapy. Gamma Knife treatment is carried out in one session (one day) under local anaesthesia and causes low physical stress to the patient. The necessary precision requires a stereotactic magnetic resonance imaging (MRI) study before radiosurgery and a stereotactic frame fixation during treatment. Generally, prescription doses of 18-22Gy are applied in Gamma Knife treatment of cerebral metastases. Doses are expressed as 'minimum' or 'prescription doses', reflecting the dose applied to the tumour periphery. This very often corresponds to the $50 \%$ isodose, resulting in an inhomogenous dose distribution within the tumour, with a maximum dose ranging between 36 and 50Gy. It has been shown that this lack of dose homogeneity is irrelevant for the outcome.

It is crucial to understand how Gamma Knife radiosurgery compares with microsurgery in the local control of metastases and prognosis. Three retrospective studies suggest that the two techniques are equivalent in terms of local control of the treated brain tumour. ${ }^{10-12} \mathrm{~A}$ recent prospective randomised study compared the efficacy of radiosurgery of brain metastases with the combined effect of open microsurgery plus WBRT. ${ }^{13}$ The minimally invasive approach with Gamma Knife radiosurgery provided equally good results to the invasive combination of open tumour resection and conventional radiotherapy with regard to survival, neurological death rates and freedom from local recurrence. Radiosurgery was associated with a shorter hospital stay, less frequent and shorter-duration steroid application and lower frequency of toxicities. Improved scores for role functioning and quality of life were seen six weeks after radiosurgery. ${ }^{13}$ Therefore, the therapeutic effect of Gamma Knife radiosurgery can be considered as equivalent to that of standard surgical approaches.

Bodo E Lippitz is a Professor of Neurosurgery at University Aachen, and Director of the Gamma Knife Centre at the Karolinska University Hospital, Stockholm. Prior to this, he served as Director of the Gamma Knife Centre at HM Queen Sophia Hospital, Stockholm. Professor Lippitz serves as President of the European Gamma Knife Society. He became a board-certified neurosurgeon in 1990.

E: bodo.lippitz@karolinska.se 


\section{Radiosurgery}

Table 1: Results of Recently Published Larger Series After Gamma Knife Radiosurgery of Cerebral Metastases

\begin{tabular}{|c|c|c|c|c|}
\hline & & Single or Multiple & Number of Patients & Local Tumour Control (\%) \\
\hline Mathieu et al., 200728 & Melanoma & Both & 244 & 86.2 \\
\hline Gaudy-Marqueste et al., $2006^{23}$ & Various & Both & 106 & 83.7 \\
\hline Pan et al., $2005^{30}$ & Lung & Both & 191 & 84-94 (volume-dependent) \\
\hline Gerosa et al., $2005^{24}$ & Lung & Both & 504 & One-year local control: 94\% \\
\hline Simonová et al., $2003^{36}$ & Various & Both & 400 & 90 \\
\hline Hasegawa et al., $2003^{25}$ & Various & Both & 172 & 87 \\
\hline Sheehan et al., $2002^{34}$ & Lung & Both & 273 & 84 \\
\hline Chen et al., 199915 & Various & Both & 190 & 89 \\
\hline
\end{tabular}

Figure 1: Patient with Breast Cancer and Multiple Cerebral Metastases

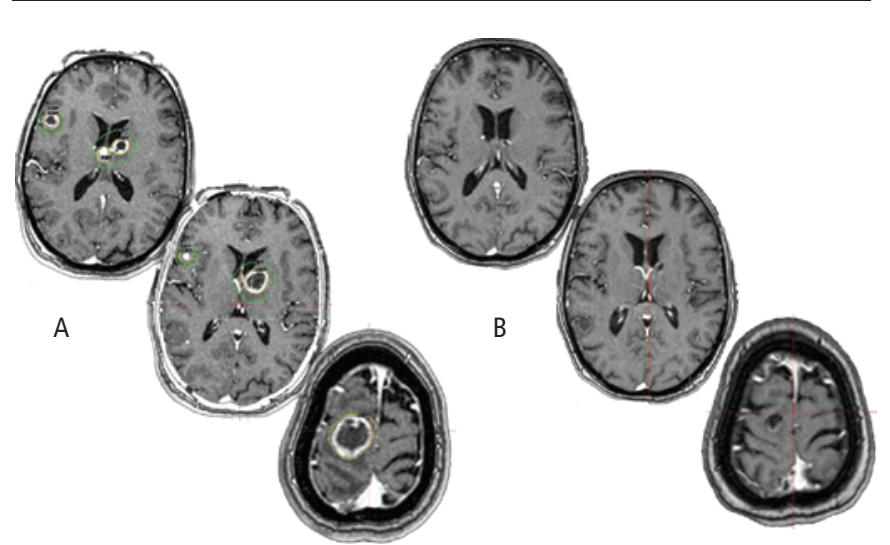

Combination of Gamma Knife radiosurgery for the larger and critically located tumours (prescription dose 19Gy) with conventional whole-brain radiotherapy (WBRT) due to general tumour spreading.

A: Magnetic resonance imaging with contrast enhancement during Gamma Knife treatment. B: Follow-up three months later.

Figure 2: Patient with Multiple Brain Metastases of Lung Cancer

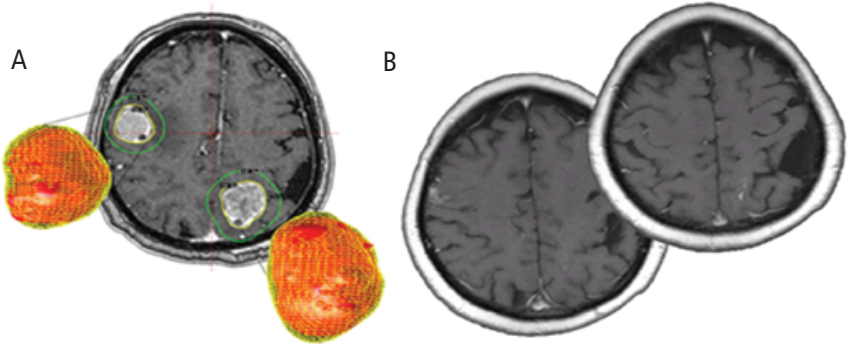

A: $3 D$ dose plan for Gamma Knife radiosurgery of the frontal and parietal metastasis (prescription dose 18Gy). B: Follow-up two months after radiosurgery demonstrates significant response with only minimal remnants detected at the original tumour site.

Recently, after a level I-III evidence-based review of the role of radiosurgery for brain metastases, the American Society for Therapeutic Radiology and Oncology (ASTRO) stated that for selected patients with up to four small brain metastases the addition of a radiosurgery boost to WBRT improves brain control compared with WBRT alone. ${ }^{14}$ However, evidence is lacking as to whether conventional radiotherapy actually provides a benefit in combination with radiosurgery. Several recent studies comprising more than 950 radiosurgically treated patients have not documented any differences in survival or local tumour control when fractionated WBRT was omitted. ${ }^{15-17}$ However, without affecting prognosis and survival, the rate of new cerebral metastases seems to be reduced when WBRT is applied. ${ }^{16}$ So far, there is no evidence that fractionated WBRT increases either local control or survival for patients who have been treated with Gamma Knife.
However, if needed in individual cases, the two methods can be combined $^{18}$ (see Figure 2).

Multiple radiosurgical sessions are considered less invasive and require only a short hospitalisation period. Therefore, the current strategy for radiosurgically treated Swedish patients with brain metastases does not include prophylactic WBRT. ${ }^{19}$ Patients who develop further tumours after initial radiosurgery are treated with several sessions of radiosurgery. WBRT is applied only in cases with a more general tumour spread when the disease in the brain can no longer be considered local. The clinical results support this regimen, which seems beneficial compared with series after WBRT. ${ }^{5-7,20}$ A prospective randomised study of patients with multiple brain metastases failed to demonstrate a survival benefit of conventional fractionated radiotherapy over radiosurgery.

A wide range of retrospective and a few prospective studies with more than 4,800 studied patients with brain metastases treated with radiosurgery have provided consistent and reproducible results with an average local tumour control between 84 and 97\% (see Figure 1). 10,12,15,17,21-38 Table 1 shows a selection of larger current Gamma Knife studies. A recent prospective randomised study documents a benefit for functional stability and quality of life for radiosurgically treated patients. ${ }^{39}$

The number of patients with multiple metastases treated with radiosurgery is constantly increasing. A recently published series compared the outcome of patients with multiple metastases after radiosurgery or WBRT in a retrospective analysis. ${ }^{40}$ The group of patients who had received only WBRT survived 6.6 months; patients in the radiosurgical group had a documented median survival time (MST) of 12.5 months. ${ }^{40} \mathrm{~A}$ European Gamma Knife study in a series of 97 patients with a median of three metastases demonstrated local control in $94 \% .{ }^{41}$ Survival has been found independent of the numbers of lesions treated. ${ }^{21,42}$

One of the few prospective randomised studies compared the effects of a radiosurgical boost in patients with multiple brain metastases. Treatment with WBRT alone resulted in local failure at one year in $100 \%$. Boost radiosurgery increased the local control considerably, resulting in only $8 \%$ local failures. The median time to local failure was six months after WBRT alone in comparison with 36 months after WBRT plus radiosurgery. ${ }^{43}$

Another multi-institutional study analysed the prognosis of patients treated with radiosurgery plus WBRT.32 The MST for the entire radiosurgical series of 502 patients was 10.7 months. The addition of radiosurgery significantly improved results compared with the median survival observed in the RTOG RPA analysis for patients treated 
with WBRT alone. ${ }^{32}$ The prospective, randomised RTOG study 9508 stated significant differences of survival for patients with solitary metastases and for younger patients with an advantage for radiosurgically treated patients. ${ }^{39}$ The RTOG study compared the outcome when radiosurgery was used as a boost after fractionated WBRT. The final interpretation that "WBRT and stereotactic radiosurgery should, therefore, be standard treatment for patients with a single unresectable brain metastasis and considered for patients with two or three brain metastases" is certainly remarkable since this study ${ }^{39}$ is the first prospective, randomised study that documented both increased local control and increased quality of life in patients treated with stereotactic radiosurgery boost.

The complication rate after radiosurgery is low. The risk of development of adverse radiation effects has been shown to be related to the irradiated volume. A typical example of the impact of the irradiated tumour volume on the risk of complications is shown in the RTOG protocol 90-05. ${ }^{18}$ Among other results, the study demonstrates that tumours with a diameter between 21 and $40 \mathrm{~mm}$ were significantly more likely to develop serious neurotoxicity compared with tumours with a diameter $<20 \mathrm{~mm}$. Therefore, generally only metastases with a tumour diameter $<30 \mathrm{~mm}$ are accepted for radiosurgery.

\section{Summary}

Gamma Knife radiosurgery provides a highly effective method of treating cerebral metastases with reliable and predictable local tumour control in the brain. Thereby, the minimally invasive approach with radiosurgery provides the time needed to treat the systemic cancer. When the established radiosurgical criteria concerning dose and tumour volumes are applied, the risk of adverse radiation effects or local recurrences is low. The addition of WBRT after Gamma Knife radiosurgery does not seem to optimise local tumour control or survival, but can be safely applied when needed in case of a more general tumour spread.
1. Schouten LJ, Rutten J, Huveneers HA, Twijnstra A, Incidence of brain metastases in a cohort of patients with carcinoma of the breast, colon, kidney, and lung and melanoma, Cancer, 2002:94(10):2698-2705.

2. Schackert $G$, Steinmetz A, Meier U, Sobottka SB, Surgical management of single and multiple brain metastases: results of a retrospective study, Onkologie, 2001;24(3):246-55.

3. Cairncross JG, Kim JH, Posner JB., Radiation therapy for brain metastases, Ann Neurol, 1980;7:529-41.

4. Pollock BE, Brown PD, Foote RL, et al., Properly selected patients with multiple brain metastases may benefit from aggressive treatment of their intracranial disease, I Neurooncol, 2003;61(1):73-80.

5. Gaspar L, Scott C, Rotman M, et al., Recursive partitioning analysis (RPA) of prognostic factors in three Radiation Therapy Oncology Group (RTOG) brain metastases trials, Int J Radiat Oncol Biol Phys, 1997:37(4):745-51.

6. Nieder C, Nestle U, Motaref $B$, et al., Prognostic factors in brain metastases: should patients be selected for aggressive treatment according to recursive partitioning analysis (RPA) classes?, Int J Radiat Oncol Biol Phys, 2000;46(2):297-302.

7. Nieder C, Andratschke N, Grosu AL, Molls M, Recursive partitioning analysis (RPA) class does not predict survival in patients with four or more brain metastases, Strahlenther Onkol, 2003;179(1):16-20.

8. Nussbaum ES, Djalilian HR, Cho KH, Hall WA, Brain metastases. Histology, multiplicity, surgery, and survival, Cancer, 1996; 78(8):1781-8.

9. Lutterbach J, Bartelt S, Stancu E, Guttenberger R, Patients with brain metastases: hope for recursive partitioning analysis (RPA) class 3, Radiother Oncol, 2002;63(3):339-45.

10. Muacevic $A$, Kreth FW, Horstmann GA, et al., Surgery and radiotherapy compared with gamma knife radiosurgery in the treatment of solitary cerebral metastases of small diameter, J Neurosurg, 1999;91(1):35-43.

11. O'Neill BP, Iturria NJ, Link MJ, et al., A comparison of surgical resection and stereotactic radiosurgery in the treatment of solitary brain metastases, Int I Radiat Oncol Biol Phys, 2003; 55(5):1169-76.

12. Schöggl A, Kitz K, Reddy M, et al., Defining the role of stereotactic radiosurgery versus microsurgery in the treatment of single brain metastases, Acta Neurochir (Wien), 2000; 142(6):621-6.

13. Muacevic A, Wowra B, Siefert A, et al., Microsurgery plus whole brain irradiation versus Gamma Knife surgery alone fo treatment of single metastases to the brain: a randomized controlled multicentre phase III trial, J Neurooncol, 2008;87(3):299-307.

14. Mehta MP, Tsao MN, Whelan TJ, et al., The American Society for Therapeutic Radiology and Oncology (ASTRO) evidencebased review of the role of radiosurgery for brain metastases, Int I Radiat Oncol Biol Phys, 2005;63(1):37-46.

15. Chen JC, O'Day S, Morton D, et al., Stereotactic radiosurgery in the treatment of metastatic disease to the brain, Stereotact
Funct Neurosurg, 1999:73(1-4):60-63.

16. Chidel MA, Suh JH, Reddy CA, et al., Application of recursive partitioning analysis and evaluation of the use of whole brain radiation among patients treated with stereotactic radiosurgery for newly diagnosed brain metastases, Int J Radiat Oncol Biol Phys, 2000;47(4):993-9.

17. Simonova G, Liscak R, Novotny J Jr, Novotny J, Solitary brain metastases treated with the Leksell gamma knife: prognostic factors for patients, Radiother Oncol, 2000;57(2):207-13.

18. Shaw E, Scott C, Souhami L, et al., Single dose radiosurgical treatment of recurrent previously irradiated primary brain tumors and brain metastases: final report of RTOG protocol 90-05, Int J Radiat Oncol Biol Phys, 2000;47(2):291-8.

19. Karlsson B, Wersäll P, Lippitz B, Kihlström L, Repeated radiosurgery versus fractionated radiotherapy in the treatment of brain metastases from renal cancer. In: Kondziolka D (ed.), Radiosurgery 1999, Basel: Karger, 2000;3:232-9

20. Lippitz BE, Kraepelien T, Hautanen K, et al., Gamma Knife Radiosurgery for Patients with Multiple Cerebral Metastases, Acta Neurochirurgica, 2004;(Suppl. 91):79-87.

21. Amendola BE, Wolf AL, Coy SR, et al., Gamma knife radiosurgery in the treatment of patients with single and multiple brain metastases from carcinoma of the breast, Cancer J, 2000;6(2):88-92.

22. Firlik KS, Kondziolka D, Flickinger JC, Lunsford LD, Stereotactic radiosurgery for brain metastases from breas cancer, Ann Surg Oncol, 2000;7(5):333-8.

23. Gaudy-Marqueste C, Regis JM, Muracciole X, et al., GammaKnife radiosurgery in the management of melanoma patients with brain metastases: a series of 106 patients without whole-brain radiotherapy, Int I Radiat Oncol Biol Phys, 2006;65(3):809-16

24. Gerosa M, Nicolato A, Foroni R, et al., Analysis of long-term outcomes and prognostic factors in patients with non-small cell lung cancer brain metastases treated by gamma knife radiosurgery, J Neurosurg, 2005;102(Suppl.):75-80.

25. Hasegawa T, Kondziolka D, Flickinger JC, et al., Brain metastases treated with radiosurgery alone: an alternative to whole brain radiotherapy?, Neurosurgery, 2003;52(6): 1318-26, discussion 1326.

26. Kim YS, Kondziolka D, Flickinger JC, Lunsford LD, Stereotactic radiosurgery for patients with nonsmall cell lung carcinoma metastatic to the brain, Cancer, 1997;80(11):2075-83.

27. Lavine SD, Petrovich Z, Cohen-Gadol AA, et al., Gamma knife radiosurgery for metastatic melanoma: an analysis of survival, outcome, and complications, Neurosurgery, 1999;44(1): 59-64, discussion 64-6.

28. Mathieu D, Kondziolka D, Cooper PB, et al., Gamma knife radiosurgery in the management of malignant melanoma brain metastases, Neurosurgery, 2007;60(3):471-81, discussion 481-2.

29. Mori Y, Kondziolka D, Flickinger JC, et al., Stereotactic radiosurgery for cerebral metastatic melanoma: factors affecting local disease control and survival, Int I Radiat Oncol Biol Phys, 1998;42(3):581-9.

30. Pan HC, Sheehan J, Stroila M, et al., Gamma knife surgery for brain metastases from lung cancer, J Neurosurg, 2005; 102:128-33.

31. Petrovich Z, Yu C, Giannotta SL, et al., Survival and pattern of failure in brain metastasis treated with stereotactic gamma knife radiosurgery, J Neurosurg, 2002;97(Suppl. 5):499-506.

32. Sanghavi SN, Miranpuri SS, Chappell R, et al., Radiosurgery for patients with brain metastases: a multi-institutional analysis, stratified by the RTOG recursive partitioning analysis method, Int J Radiat Oncol Biol Phys, 2001;51(2):426-34.

33. Sansur CA, Chin LS, Ames JW, et al., Gamma knife radiosurgery for the treatment of brain metastases, Stereotact Funct Neurosurg, 2000;74(1):37-51.

34. Sheehan JP, Sun MH, Kondziolka D, et al., Radiosurgery for non-small cell lung carcinoma metastatic to the brain: longterm outcomes and prognostic factors influencing patient survival time and local tumor control, I Neurosurg, 2002;97(6):1276-81.

35. Shiau CY, Sneed PK, Shu HK, et al., Radiosurgery for brain metastases: relationship of dose and pattern of enhancement to local control, Int I Radiat Oncol Biol Phys, 1997;37(2): 375-83.

36. Simonová G, Roman L, Radiosurgery in the treatment of malignant brain tumors, Expert Rev Anticancer Ther, 2003;3(6):879-90.

37. Sneed PK, Lamborn KR, Forstner JM, et al., Radiosurgery for brain metastases: is whole brain radiotherapy necessary? Int J Radiat Oncol Biol Phys, 1999;43(3):549-58.

38. Wowra B, Siebels M, Muacevic A, et al., Repeated gamma knife surgery for multiple brain metastases from renal cell carcinoma, J Neurosurg, 2002;97(4):785-93.

39. Andrews DW, Scott CB, Sperduto PW, et al., Whole brain radiation therapy with or without stereotactic radiosurgery boost for patients with one to three brain metastases: phase III results of the RTOG 9508 randomised trial, Lancet, 2004; 363(9422):1665-72.

40. Serizawa T, luchi T, Ono J, Set al., Gamma knife treatment for multiple metastatic brain tumors compared with wholebrain radiation therapy, J Neurosurg, 2000;93(Suppl. 3):32-6.

41. Schöggl A, Kitz K, Ertl A, et al., Prognostic factor analysis for multiple brain metastases after gamma knife radiosurgery: results in 97 patients, J Neurooncol, 1999;42(2):169-75.

42. Kim DG, Chung HT, Gwak HS, et al., Gamma knife radiosurgery for brain metastases: prognostic factors for survival and local control, I Neurosurg, 2000;93(Suppl. 3): 23-9.

43. Kondziolka D, Patel A, Lunsford LD, et al., Stereotactic radiosurgery plus whole brain radiotherapy versus radiotherapy alone for patients with multiple brain metastases, Int J Radiat Oncol Biol Phys, 1999;45(2):427-34. 